International Journal of Linguistics, Literature and Translation

ISSN: 2617-0299 (Online); ISSN: 2708-0099 (Print)

DOI: 10.32996/ijltt

Journal Homepage: www.al-kindipublisher.com/index.php/ijltt

\title{
An Investigation into the Translation Techniques Used in the Female Characters in the Comic of Pasutri Gaje
}

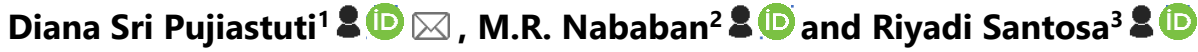 \\ ${ }^{123}$ Master of Linguistic, Faculty of Cultural Science, Sebelas Maret University, Indonesia \\ $\triangle$ Corresponding Author: Diana sri pujiastuti, E-mail: dianasripujiastuti@student.uns.ac.id
}

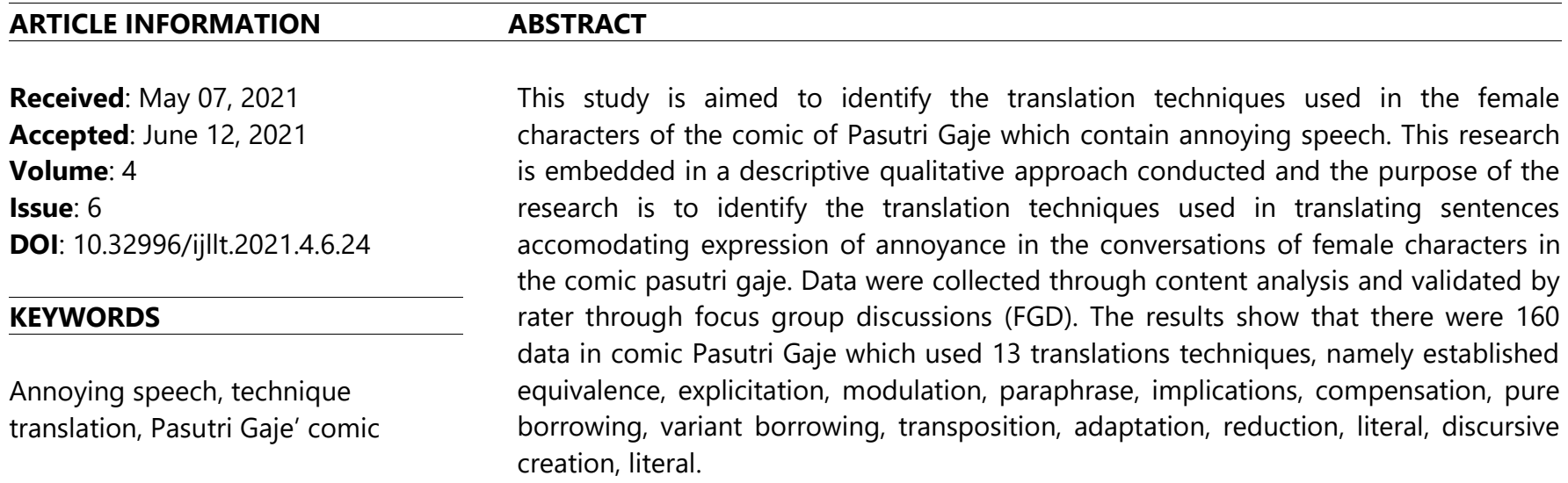

\section{Introduction}

In translating a comic or literary work, a translator needs to have a competence in two languages and abilities in other fields of science. This is in line with the opinion of Nababan (2003: 12-13), who states that the science of translation is industrial because science also receives many contributions from different branches of knowledge such as linguistics, psychology, sociolinguistics, pragmatics, communication science, philology, lexicology and so on.

This study uses one type of literary work as the object of translation, namely comics. Usually, comics take a time setting in what is happening or it can be said that the time always occurs in everyday life. One of the uniqueness of comics is that they have been translated into various languages, one of which is English by comic fans who are in fan translation. As well as this, readers will be brought in the marriage life of the main character and the social environment.

Based on Scott McCloud from the book Understanding Comics: The Invisible Art, 1993, MS.Gumelar (2011: 6) states that a comic is juxtaposed pictorial and other images in deliberate sequence, intended to convey information and/or produce an aesthetic response in the reader. McCloud (1993) emphasizes that comics are images that are lined up in a deliberate order, intended to convey information or generate an aesthetic response from the reader. In his book, MS Gumelar (2011: 7) also explains that comics are sequences of images arranged according to the purpose and philosophy of the maker until the message in making a translation work. Every translator is always faced with several problems, such as word choice, cultural equivalence between SL with $\mathrm{TL}$, as well as the language style in conveying the content and message expected by the author. The translator must make the right decision so that the community in TL can understand the translation. Therefore, choosing the right technique can create a translated work that look like a translated one.

Molina Albir (2002: 509) states that "translation techniques as procedures to analyze and classify how translation equivalence works". In other words, the translation technique is a tool used to analyze and classify SL equivalent words in TL. In its use, the translation technique has five characteristics: influencing the results of translation, classifying techniques based on $\mathrm{SL}$ and $\mathrm{TL}$,

\section{K C AL-KINDI CENTER \\ $\mathbf{R}$ D FOR RESEARCH AND DEVELOPMENT}

Your gateway to world-class research

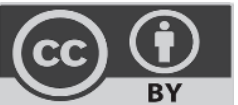

Published by Al-Kindi Center for Research and Development, London, United Kingdom. Copyright (c) the author(s). This open access article is distributed under a Creative Commons Attribution (CC-BY) 4.0 license 
affecting micro-units in the text, being discursive and contextual in nature, and functional. Furthermore, Molina Albir classifies translation techniques into 18 types as follows:

a. Adaptation is a technique that replaces the translation of cultural elements contained in the BSU to be more accepted in the BSA. Example: change from Oh my God to Ya Ampun in Indonesian translation.

b. Amplification is a technique that provides details of terms not found in BSa, namely by adding information and explicit paraphrasing. This technique is the opposite of reduction. Example: translation from English to Indonesian by adding 'Taman Makan Kuno Khusu Protestan' in the name of the place of Old Protestant Cemetery.

b. Lending is a technique of taking a word or expression directly from BSU, in terms of both phonetic and morphological. Loan bias is pure (pure borrowing), also referred to as loan without adjustment, such as the use of the English word smoking area in the Indonesian language to describe areas for smoking. Sometimes this technique is naturalized according to a target language rule called naturalization (naturalized borrowing), also defined as an adjustment to spelling or pronunciation, as in the word actress in Indonesian which is borrowed from the English word actress.

c. Calque is a literal translation technique that takes lexical rules or structures directly into BSa, but only general terms.

d. Compensation is a translation technique used to move BSu elements from certain places and units to other places and units in BSa. This is done because the stylistic effect (force) on BSU cannot be applied to BSa. This technique is the same as the conception technique. Example: the English expression a pair of scissors which is translated into Indonesian into $a$ pair of scissors.

e. Technical description is a technique that is used to replace a term in BSu with a description in terms of form and function in BSa. Example: translating egg tarts from English into Indonesian is usually called milk pie.

$\mathrm{f}$. Discursive Creation is a technique for displaying unexpected similarities because they are completely different from $\mathrm{BSu}$ and out of context. This is done to attract the attention of potential readers. This technique often appears in the translation of film, book or novel titles. Example: the English translation of the title of the novel Shopaholic and Sister is translated into Indonesian to become The Crazy Shopping Has Big Brother.

g.Established Equivalent is a technique for using the colloquial term within the meaning lexicon and is commonly used. This technique is also used when a term in BSU has more than one term in BSA, so that the closest one is chosen according to the context. Example of the English word blue is translated to be sad because it is the closest to the context.

h. Generalization is a technique that uses a more general term without describing it in more detail. This was done because the BSa did not have a specific equivalent. For example: the translation of the English mansion into Indonesian becomes a house.

i. Linguistic amplification is a technique to add linguistic elements in BSa to make it more in accordance with the rules and easier to understand. This technique is often used in consecutive interpreting and dubbing.

j. Compression Linguistics is the techniques to reduce linguistic elements within the BSA. This technique is the opposite of the linguistic amplification technique. This technique is commonly used in simultaneous interpretation and subtitling. For example, the translation of a phrase from English I want you to know becomes Know in Indonesian, instead of using a phrase with the same number of words I want you to know.

k. Literal Translation is a technique for translating word for word by paying attention to the target language's structure, but the translator does not relate it to the context. For example, the proverb in English is killing two birds with one stone which translates to killing two birds with one stone, instead of using the Indonesian proverb while diving to drink water.

I. Modulation is a translation technique by changing the point of view and focusing on cognitive aspects in the source language, both in terms of structural and lexical. Even so, the translation results will still give the same message. For example: a translation of the English phrase You are going to be a mother in Indonesian becomes You will have children.

m. Particularization is a technique to use more specific and concrete terms, such as translating exercise in English into gymnastics in Indonesian. This technique is the opposite of the generalization technique.

Page | 212 
n. Reduction is a technique by compressing elements in the BSA information but does not eliminate the element of information. An example of a translation with this technique is the translation of the English phrase Now it's Ramadhan, the month of fasting for Moslem to become now Ramadan in Indonesian.

o. Substitution is a technique used to replace linguistic elements with paralinguistic and vice versa. For example, the translation of the gestus he shakes his head into an expression he disagrees with. This case occurs in interpreting.

p. Transposition is a the technique used to replace the BSu grammatical categories with BSa, as in the translation of words in English adept into phrases in Indonesian is very skilled.

q. Variation is a technique that replaces linguistic elements with paralinguistics, and usually affects aspects of linguistic variation. These changes can have an impact on linguistic variation. For example, changes in character dialects in film translation, or changes in tone in translating literary works for children.

\section{Methodology}

A qualitative descriptive approach is used in this study. The source in this study is a comic by Annisa Nisfihani, namely Pasutri Gaje, published by Line Webtoon as an online comic platform published for the first time in 2015. A collection of webtoon fans has translated the comic for webtoon readers on the same platform, namely fan translation managed by line webtoon of the same title. The incident in this comic is the utterance or narrative in the daily life of all the female characters in the comic Couples Gaje. Primary information consists of linguistic data and translation data. Linguistic data is in the form of sentences containing exasperation. Secondary data of this research is in the form of suggestions or recommendations from references such as novel reviews, publication texts, and sociolinguistic approaches relevant to cultural issues. The data sources of this research are documents and the focus group discussion results (FGD).

The source of the document is in the form of written Indonesian text (source language) of the comic Pasutri Gaje by Annisa Nisfihani sessions 1 to 2 published in 2015, the translated novel using the same title in 2016 which was translated in fan translation, journals on speech acts and translation of speech acts for additional reference in developing studies as secondary data. The data analyzed in the analysis are data on the use of speech acts, the translation techniques and the impact of the translation techniques on the quality of translation.

\section{Findings and Discussion}

Translation techniques were analyzed on each sentence data. To identify translation techniques using theory by Molina \& Albir (2002: 509). The forms of translation techniques and their frequency of use can be seen in the table below.

Table 4.1 translation techniques

\begin{tabular}{|l|l|l|l|}
\hline No. & Translator Techniques & amount & Percentage \\
\hline 1 & MatchesLazim & 425 & $58.9 \%$ \\
\hline 2 & Explicit & 84 & $11.6 \%$ \\
\hline 3 & Modulsi & 73 & $10.1 \%$ \\
\hline 4 & Paraprase & 48 & $6.6 \%$ \\
\hline 5 & Implicit & 31 & $4.3 \%$ \\
\hline 6 & Pure Borrowing & 22 & $3.0 \%$ \\
\hline 7 & Transport & 10 & $1.4 \%$ \\
\hline 8 & Compensation & 7 & $1.0 \%$ \\
\hline 9 & Discrusive creation & 7 & $1.0 \%$ \\
\hline 10 & Reduction & 6 & $0.8 \%$ \\
\hline 11 & Literal & 6 & $0.8 \%$ \\
\hline 12 & Variant Borrowing & 2 & $0.3 \%$ \\
\hline 13 & Adaptation & 1 & $0.1 \%$ \\
\hline amount & & 722 & $100 \%$ \\
\hline
\end{tabular}


In the table above, it can be seen that there are 13 types of techniques used in translating utterances that contain annoyance. The most dominant technique used is the common equivalent technique of 425 data with a presentation of $58.9 \%$, and the second tank goes to the modulation technique with a number of 73 in a percentage of $10.1 \%$. As well as this, the paraphrase technique of 48 with $6 \%$, a reduction technique including 6 experiences $(0,8 \%)$. Some other figures are the imitation technique, which is 31 with a $4.3 \%$, the compensation technique 7 with a percentage of $1.0 \%$, the variant borrowing technique 2 with a of $0.3 \%$, and the explicit borrowing technique is 84 with a $11.6 \%$. This table also shows transposition techniques which 10 with a $1.4 \%$, and reduction techniques figures of 6 with (0.5\%).Last but not least, pure borrowing techniques are $223.0 \%$, and discursive creation techniques witness 7 with $1.0 \%$ and techniques. The adaptation of 1 with a percentage of $0.1 \%$ is the least used technique in irritating utterances in the comic.

a. MatchesLazim

Bsu: ouch! really bother?

Bsa: gezz! so bothered any way?

The data example above shows that the k alimat contains the utterance of annoyance "ouch! really troublesome? " translated using the usual equivalent translation technique into "gezz! so bothered any way? ", because the sentence or word above is very commonly used or often used in everyday life in the target language.

b. Modulation

Bsu: ah! I'm not in the mood! I am sleepy!

Bsa: ah! I am not in the mood anymore! lam going to sleep

For example, in the data above, the phrase "I'm sleepy" is translated into "I am going to sleep" using a modulation translation technique. The use of this technique only changes his perspective, but the meaning of the message conveyed is still the same as the message in the source language.

c. Paraphrase

Bsu: where else do you have a stomachache like this?

Bsa: and now I have got a stomache

The data example above has different concepts in the source language and the target language, but the message does not change, namely that Adel's character feels stomach pain which may be because of the fact that he wants to go to the bathroom to urinate or maybe also because he is late to eat.

\section{d. Reduction}

Bsu: yeah! isis wind mah yes, maybe it was just finished "monthly" yesterday

Bsa: issh! Its imposible my period just enden yesterday

For example in the data above, the translator uses a reduction technique in sentences containing annoyed utterances that are uttered by the character of Adel to his friend to show the annoyance he is always asked about pregnancy. The translator uses a reduction in the word "just enden" in the target language to compress the information.

e. Explicit

Bsu: annoying !!

Bsa: this is ridiciliouse !!

The example above, that the word "this" is an additional word to further emphasize the sentence "ridiciliouse" in the source language does not add any sentences or words to reinforce the meaning of the sentence "sucks".

f. Implicit

Bsu: Don't pretend you don't know, bro! Same thing last night.

Bsa: don't pretend like you don't know what happened last night

In the example above, the translator implies a message in the source language in the sentence "don't know" through the word "don't know" into an implied message in the word but does not change the target language's structure. 


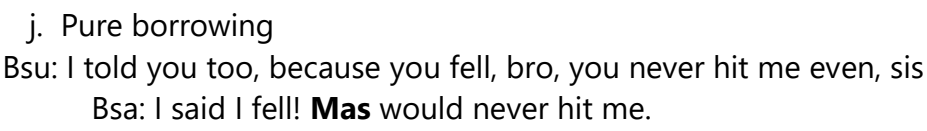

An example of the data above is that the translator does not change the word "mas" as a pure borrowing technique which in the target language does not have a substitute for the word "mas" as in the source language so that the translator continues to use the original word of the source language word.

h. Literal

Bsu: After dinner, continue playing the game, even though who was the one this afternoon?

Bsa: after having dinner, just continue game. Who is the one asking for "it:

The example of the data above is that in the sentence "after dinner, continue playing the game" the translator does not change the language structure from the source language to the target language and translate literally without changing the order of the language to "after having dinner, just continue game"

i. Compensation

Bsu: I can't just sit around waiting !!

Bsa: I can not just sit and do nothing while waiting for him

The data above shows that the word "just sit" is not only always following the next word "sitting menunngu" but can be a separate sentence, namely "just sit: or" just sitting ". This expression was uttered by the character of Adel who was annoyed to wait so long because his younger brother did not come home soon.

j. Discursive creation

Bsu: the worse my image in his eyes

Bsa: his image of me will definitely

The data above shows that the translator uses the translation technique of discussive creations in the sentence "his image of me will definitely" in the target language. The translator uses a language in different froms compared to the source language to attract attention by introducing various other creations to the translation results.

k. Transposition

Bsu: why don't you chat with me when my brother is coming

Bsa: why did not you tell me that the guy will coming

The example above shows that "why" is a sign that there is a change in the translation from a passive sentence in the source language to an active sentence in the target language. The character's utterance was to emphasize his frustration with his brother who suddenly came without notice.

I. Variant borrowing

Bsu: It turns out that the title "playboy" is not just a rumor, huh! Basic sis vian

Bsa: turn out the playboy is not just rumors! damn vian

The data above shows that the word "playboy" is a loan word from English. The target language still uses the same word, but the use of this variant borrowing technique does not change the meaning of the target language. This sentence was pronounced ningsih to show resentment at being forced to interfere in an argument between doctor vian and a woman.
m. Adaptation
Bsu: istigfar you rani!
Bsa: goodness rani !!

The example above shows that the word "istigfar" is changed to the word "goodness" by the translator because the cultural elements in the word "goodness" are more accepted in the target language. The above expression is the utterance of the mother who was annoyed at Rani who had not yet realized her mistake. 


\section{Conclusion and Suggestions}

This study is aimed to identify the translation techniques used in the female characters in the comic of Pasutri Gaje, which contain annoying speech. Based on the study results, there were 160 identified data containing annoyed utterances produced by female characters. In addition, 13 translation techniques were taken into consideration. The most widely used technique of translating the familiar equivalent is 425 data. This shows that the translator wants to convey the message as accurately as possible using the language commonly used in the target language. Several translation techniques produce good translations, namely common equivalents, explanations, modulation, paraphrase, imitation, while for literal translation techniques and discursive creations, the translation results are not in accordance with the context. Finally, the reduction translation technique results in an inaccurate translation because it removes some parts of messages that are translated into the target language. Translation techniques adaptation to cultural terms will make the translation results less acceptable to readers because they still use cultural terms from the source language that the target language readers do not understand.

Funding: This research received no external funding

Acknowledgements: This paper and the research behind it would not have been possible without the exceptional support of my supervisor, M.R. Nababan and Riyadi Santosa. Their enthusiasm, knowledge and exacting attention to detail have been an inspiration and kept my work on track.

Conflicts of Interest: The authors declare no conflict of interest.

\section{References}

[1] Zanettin, F. (ed.) (2008). Comics in Translation, Manchester: St Jerome Publishing.

[2] Nababan, MR 2003. Theory of Translating English. Yogyakarta: Student Library.

[3] Nababan, M., Nuraeni, A., and Sumardiono. (2012). Translation Quality Assessment Model. Journal of Linguistic and Literary Studies

[4] Nida, A. \& Charles, T. (1982). The Theory and Practice of Translation. Leiden: EJ Brill.

[5] Molina, L., \& Albir, AH (2002). Translation Techniques Revisited: A Dynamic and Functionalist Approach . Meta: Translators' Journal, 47(4). Retrieved from: http://id.erudit.org/iderudit/008033ar

[6] Gumelar, M. (2011). Comic Making. Jakarta: PT Index

[7] Halliday, M. (1985). An Introduction to Functional Grammar . London: Edwarl Arnold, 1985.

[8] McCloud, S. (1993). Understanding Comic, Jakarta: Gramedia Publisher

[9] Rota, V. (2008). Aspects of Adaptation: The Translation of Comic Formats in Comic Translation. Manchester: St. Jerome Publishing.

[10] Searle, J, \& Daniel, V. (1985). Foundation Of Illocutionary Act. Cambridge. England, Cambridge University. http: //www.illocutionary acts.com. 